\title{
Immersion: the key to a good gaming experience
}

\author{
Noirin Curran
}

School of Applied Psychology, UCC

\section{Immersion and games}

The first ever reference to games in history, a description of the origin of games by a figure from the 5th Century BC, Herodotus, appears alongside the first mention of immersion. Herodotus told a story about the King of the Ancient Lydians who was said to have invented games. The King was faced with a dilemma when he found that a famine had hit his land and he did not have enough food to feed his people; however, he came up with a very interesting solution. The King decided that his citizens would be allowed to eat during the first day, and for the second day they would become so deeply involved, immersed, in dice games, that they would forget about being hungry and would not need to eat, and this pattern would continue, with the people playing games instead of eating every second day. By this method, the King's people survived the famine, or so the story goes.

"Immersion" can be described as a state of being deeply engaged or involved in an activity, although when mentioned in the context of gaming, the immersive response is a much richer concept. While the concept of immersion is significant for games, applications of immersion can also be seen in many different areas. Certain types of educational settings use immersion as part of their teaching methods, particularly in teaching languages. When students are sent to the Irish-speaking Gaeltacht or to French speaking areas for a period of time and instructed to speak only the language of the area, this is an example of immersion learning. Immersion takes place in more ordinary classroom based settings also, where teachers refuse to speak the student's native language, and will instead only communicate through the language that the students are attempting to learn.

Immersion has also had applications in acting, as certain actors use the technique of Method Acting to "get into character" and try to think or feel as the character would, in order to give a very lifelike and realistic performance. Alternatively, on the other side of the screen, viewers of a film or television show can get very immersed in the action on the screen, as can be seen, for example, in an instance where you feel as if you're on the edge of your seat, anxious and full of suspense while you watch a particularly tense scene in a psychological thriller. 
Although immersion has many applications in areas such as education, acting, reading books or watching television and films, immersion and gaming have been intertwined since their first mention in history. Currently, I am carrying out research in the area of immersion and games, with the end goal of creating a questionnaire which will measure the strength of immersion as encountered by the player in a given gaming experience.

\section{Immersion and the gaming community}

Today, it is nigh impossible to imagine our lives without the existence of the internet. Over 1.7 billion people worldwide now have access to the World Wide Web. Internet access has become widespread, and the ways in which an individual can go online are increasing, especially with the introduction of Smart Phones and Tablets for internet use. Online gaming is currently one of the most popular forms of internet-based entertainment, involving millions of people each day. To give a sense of scale: 12 million individuals play one of the most popular of these online games, World of Warcraft, and that is merely one particular game within one genre of games, just a single example of the huge variety of games available today. Gaming is a multi-billion dollar industry.

Recently, immersion has become very popular within the gaming community and, therefore, the gaming industry. It has been found that immersion is one of the major motivations for players to choose a game, often being portrayed as "key to a good gaming experience". As a result, immersion has become a very important word for games developers. In the gaming industry, developers often characterise their games as being "immersive" as the act of advertising a new game in this manner results in great games sales and huge profits. The strange thing about this is that many games developers do not actually understand what immersion is, and they have no way of measuring how immersive their new game is, yet they continue to tell the public how immersive their games are, and often end up selling millions of copies of their products as a result.

\section{Measuring immersion}

Many have attempted to define immersion, yet none of these definitions have yet been widely accepted. Similarly, a few individuals have put forward measures of immersion, or theories about the different strengths of immersion that can be experienced by those who play games, yet none of these have been accepted as the definitive word on immersion. The development of a scale of levels of involvement is still at an early stage, but the area is attracting more interest in recent times, given the importance now placed on immersion by games developers.

Despite huge interest in the area, that concept of immersion has proved very difficult to 
pin down and measure. My research has a two main aims. Firstly, the research aims to analyse the experience of immersion from the point of view of the player of a game. Secondly, the research aims to develop a questionnaire which will measure the quality and degree of immersion as experienced by the player in a given occasion of gaming. The first aim of this research has been completed.

Initially, I asked open ended questions on an online discussion forum (RPG.Net) in order to investigate the experience of immersion. The users of this forum are generally involved with a variety of types of games, from traditional table-top games to modern online computer games and everything in between. When I first posted the questions, I included the description of immersion by Coomans and Timmermans as the "feeling of being deeply engaged where people enter a make-believe world as if it is real." Thirty eight individuals responded, and they talked at length about their experiences of immersion, the importance of these experiences for them, the reasons that they had become immersed and the reasons that they were involved in playing games. As well as this, there was an interesting outcome which was quite unexpected: some of those who responded began a heated debate about the description of immersion that had been posted, and discuss their beliefs about how immersion should be defined and what it means to them!

Two interesting items emerged from the analysis of these discussions. As anticipated, a definition of immersion as it pertains specifically to gamers emerged, which will be useful in discussing immersion with specific reference to games. This definition describes immersion as a subjective state of intense involvement in an imaginary setting, where an individual may either identify with or adopt a character or a setting (or both). If the individual identifies with a character they may adopt some, or all, of the character's attributes. If an individual identifies with a setting some or all of the demands of the setting become the attentional focus. An immersive response can vary in strength and duration, at its most extreme, causing loss of a sense of self or reality and feeling as if one is the character or is "in" the setting.

Alongside this definition, a new classification of immersion as containing two separate types of immersion also emerged.

The first type of immersion, termed Cognitive Immersion, is frequently seen in the context of fantasy games, but also often occurs in watching a film or reading a book. This is the type of immersion that is most often associated with Role-Playing Games, and this can be seen in the media's depiction. In the portrayal of Role-Playing Games in popular media, game players are regularly depicted as being entirely immersed within a RolePlaying Game. That is, the individuals become involved in a Role-Playing Game and for the remainder of the action, the onscreen scene cuts 'into' the game, where the players are depicted dressed as their game characters and existing purely in the imaginary world of the game. This type of immersion occurs when an individual becomes deeply involved in a fantasy world in which they may adopt the feelings, thoughts and mannerisms of a 
character, communicate in-character with the other characters in this world, and forget themselves and the real world. Occasionally, the character can even appear to take on a life of its own, and the player of a game can forget their real world surroundings for a short period of time.

The second type of immersion, Visceral Immersion, relates to the sensation of being immersed in the adrenaline of a situation, where the individual feels a rush of adrenaline and gets caught-up-in-the-action. In this type of immersion, the individual is not necessarily absorbed in a character or role-playing to any extent, but they become immersed in the action of the game, the strategising or tactics, and are swept away by this rather than being swept away by the world or the characters. Again, they have the possibility of becoming immersed such that they can forget what is going on around them. An example of this may be in the first scene of a horror film where an unknown victim splits off from her friends and walks into a dark room alone: often this type of scene causes people to shout warnings at the screen even though they realise that the serial killer's first victim cannot possibly hear them and heed the warning. This type of immersion can also be seen in shooting games where the player's health points are dropping rapidly and they feel a rush of adrenaline as they attempt to survive and find their enemy, or in an action film where a generic hero abseils down the face of a building as his nemesis tries to cut the rope before he safely reaches the ground. This immersion can also happen in slightly calmer settings, such as when an expert chess player may become completely absorbed in the game and planning their next moves, such that they forget the world around them.

As part of this ongoing research, a review of studies has been conducted in the area of individual differences in game players, including information related to demographics, personality and identity. In the media, and in the general population, there is a stereotype of a gamer as being young, male, intelligent yet anti-social "nerds". In fact, very little evidence has been found to show that there is any difference between the general population and gamers in any of these respects. Interestingly, minimal evidence has been found to exist for the link between video games and violent behaviour, despite the vast media interest in this area. This paper suggests that the general stereotype of gamers does not hold credit.

Noirin Curran is a PhD candidate in the School of Applied Psychology and is a member of the People and Technology Research Group. The author wishes to thank her supervisor Dr. Jurek Kirakowski, School of Applied Psychology, University College Cork.

\section{Suggested Reading}

Curran, Noirin. Stereotypes and Individual Differences in Role-Playing Games. International Journal of Role-Playing, 2. 2011. <URL: http://www .marinkacopier .nl/ijrp/ wp-content/issue2/IJRPissue2-Article4.pdf $>$ 